\title{
Circulating microRNAs: macro-utility as markers of prostate cancer?
}

\author{
Luke A Selth, Wayne D Tilley and Lisa M Butler
}

Dame Roma Mitchell Cancer Research Laboratories and Adelaide Prostate Cancer Research Centre, University of Adelaide and Hanson Institute, Adelaide 5000, Australia

(Correspondence should be addressed to W D Tilley; Email: wayne.tilley@health.sa.gov.au; L A Selth; Email: luke.selth@adelaide.edu.au)

\begin{abstract}
The realization that microRNAs (miRNAs) are frequently deregulated in malignancy has had a major impact on cancer research. In particular, the recent finding that highly stable forms of miRNAs can be accurately measured in body fluids, including blood, has generated considerable excitement. Here, we discuss the potential of blood-based circulating miRNAs as diagnostic, prognostic, and predictive biomarkers of prostate cancer. We also describe practical considerations that may influence identification and/or measurement of miRNA biomarkers in the circulation. Finally, evidence is prevented for the emerging concept that circulating miRNAs are actively released by their cells of origin and can modulate gene expression at distal sites. These mobile miRNAs, which we term 'hormomirs' because of their hormone-like characteristics, could act as local or long-range signals to maintain normal homeostasis or influence the development and progression of diseases such as cancer.
\end{abstract}

Endocrine-Related Cancer (2012) 19 R99-R113

\section{Micromanagers of gene expression}

MicroRNAs (miRNAs) are small nonprotein-coding RNA molecules that act to regulate gene expression. The genes encoding miRNAs are, in general, regulated and transcribed in the same manner as protein-coding genes, generating a primary miRNA transcript of several hundred nucleotides in length. After multiple processing steps in both the nucleus and cytoplasm, an active 21-23nt molecule, termed the mature miRNA, is generated. Mature miRNAs are incorporated into RNA-induced silencing complexes (RISC) and bind with imperfect complementarity to sequences in specific mRNA targets. Formation of these partial miRNA:mRNA duplexes results in decay of the mRNA transcript or, more commonly, inhibition of its translation. The synthesis, transport, and mechanism of action of miRNAs have been comprehensively described in a number of recent reviews (Winter et al. 2009, Djuranovic et al. 2011, Winter \& Diederichs 2011).

Given that miRNAs can bind to multiple mRNA species and that over 1400 human miRNAs have been identified (miRBase release 17; Kozomara \& Griffiths-Jones 2010), the miRNA repertoire of a cell can profoundly impact gene expression programs. Indeed, it has been estimated that $\sim 60 \%$ of all protein-coding genes are directly targeted by miRNAs (Friedman et al. 2009). It is therefore not surprising that critical functions for miRNAs have been demonstrated in a diverse array of normal physiological processes, including development, cell behavior, stress responses, and survival (Bushati \& Cohen 2007). The importance of miRNAs in cellular control of gene expression is highlighted by the observation that loss of Dicer (Dicerl), an RNase required for miRNA biogenesis, results in embryonic lethality in mice (Bernstein et al. 2003) and zebra fish (Wienholds et al. 2003).

\section{miRNAs and cancer}

In addition to maintaining the normal growth, development, and health of an organism, miRNAs can influence the development and progression of malignancy. Indeed, altered miRNA expression is a common characteristic of tumorigenesis (Croce 2009). Like protein-coding RNAs, miRNAs have the potential to either promote (oncomirs) or inhibit (tumor 
suppressor miRNAs) cancer (Calin \& Croce 2006, Croce 2009). Oncomirs target tumor suppressor genes and are commonly upregulated in cancer; for example, miR-21 is frequently elevated in many tumor types and causes silencing of PTEN and other tumor-suppressing genes (Meng et al. 2007, Pan et al. 2011). Conversely, miRNAs are defined as tumor suppressors if they target oncogenes, such as the KRAS-targeting let-7 family members, which are frequently lost or downregulated in malignancy (Peter 2009, Boyerinas et al. 2010).

Aberrant activity of miRNAs in cancer reflects both quantitative and qualitative effects (Schaefer et al. 2010). A quantitative effect refers to a change in miRNA expression or concentration, which can occur by genomic alterations, mutations, or epigenetic changes to miRNA genes, modified regulation of miRNA genes (e.g. by transcription factors), and/or deregulated miRNA biogenesis and transport (for review, see Koturbash et al. (2010)). For example, genes encoding miRNAs are frequently located at the genomic regions associated with loss of heterozygosity, amplification, or break points (Calin et al. 2004). Qualitative changes can occur when an miRNA loses or gains a recognition sequence, either by mutations or by polymorphisms in the miRNA or its target (Schaefer et al. 2010). Emerging evidence suggests that such functional alterations in miRNA activity may occur frequently in cancer (Blitzblau \& Weidhaas 2010): one example is a common single nucleotide polymorphism in the KRAS $3^{\prime}$-UTR that disrupts a let-7 target site and confers a $\sim 2.3$-fold increased risk for developing non-small cell lung cancer in smokers (Chin et al. 2008).

As miRNA function is dictated by the relative availability of its target mRNAs, tissue-specific expression patterns of miRNAs and mRNAs enable a specific miRNA to possess disparate roles in cells of different lineages (Landgraf et al. 2007, Friedman et al. 2009). Analogously, miRNAs can function divergently in cancers of different origins. An extreme example is miR-125b, which is an oncogene in prostate cancer (PCa), thyroid cancer, neuroblastoma, and glioblastoma but acts as a tumor suppressor in ovarian and breast cancer (for review, see Cortez et al. (2011)). Such dichotomy in respect to miRNA function in cancer is not uncommon and is likely to become more widely recognized as reports of the functional roles of novel miRNAs in different cancers continue to emerge. This phenomenon highlights the importance of identifying miRNA target genes and integrating miRNA/mRNA tissue expression profiles.

\section{miRNAs as biomarkers of malignancy}

An increasingly large body of work suggests that miRNA profiles are a rich source of pathognomonic information. This paradigm was first hinted by Lu et al. (2005), who demonstrated that miRNA expression signatures accurately distinguished between tumors of different developmental (i.e. epithelial vs hematopoietic) and tissue origin and could even partition tumors within a single lineage (acute lymphoblastic leukemia). Moreover, such signatures were remarkably useful tools for the diagnosis of tumors of histologically uncertain cellular origin ( $\mathrm{Lu}$ et al. 2005). Since that time, other studies have highlighted the potential of miRNA expression signatures to define pathological environments (Landgraf et al. 2007, Rosenfeld et al. 2008, Tam 2008, Rosenwald et al. 2010). miRNAs have other requisite traits of a disease biomarker. First, miRNAs are exceptionally stable in various types of clinical samples, including formalin-fixed paraffinembedded tissues (Xi et al. 2007). Secondly, miRNAs can be readily detected using specific and sensitive quantitative RT-PCR (qRT-PCR)-based assays, providing a significant advantage for analyzing samples that are scant or poorly preserved (Tam 2008). Moreover, these assays are readily amenable to multiplexing, an important consideration given the emerging appreciation that signatures comprised of multiple biomarkers are likely to possess greater diagnostic or prognostic accuracy compared with single analytes. Finally, most miRNAs are highly conserved between species, allowing the use of animal models of disease for preclinical discovery studies.

In 2008, a number of groups isolated cell-free circulating miRNAs from blood fluids (i.e. serum and plasma) and demonstrated that the levels of certain miRNAs were altered in response to various malignancies (Chim et al. 2008, Lawrie et al. 2008, Mitchell et al. 2008), raising the exciting possibility of using blood-based miRNA testing to assist in disease detection and management. Since those seminal papers, the utility of cell-free miRNAs as biomarkers of cancer has become increasingly apparent in preclinical studies: serum or plasma miRNAs have been used for cancer diagnosis and staging (Huang et al. 2010, Liu et al. 2010, Pu et al. 2010, Roth et al. 2010), prognosis (survival or relapse; Pu et al. 2010, Li et al. 2011, Liu et al. 2011), and predicting response to therapy (Zhang et al. 2010a). More recently, miRNAs have been isolated in many other body fluids, including urine, saliva, semen, tears, breast milk, and amniotic fluids, suggesting that their release or export occurs from most tissue and cell types (Hanke et al. 2009, 
Park et al. 2009, Weber et al. 2010). Interestingly, miRNA profiles can define the molecular taxonomy of body fluids in forensic samples, further highlighting their diagnostic potential (Hanson et al. 2009).

Other recent reviews have eloquently described the potential of miRNAs derived from body fluids as noninvasive biomarkers for different tumor entities (Brase et al. 2010, Cortez et al. 2011). Here, we will specifically discuss the application of circulating (serum and plasma) miRNAs to detect and manage PCa.

\section{Circulating miRNAs as novel biomarkers of $\mathrm{PCa}$}

\section{Better tools to diagnose and prognosticate $\mathrm{PCa}$ are urgently required}

$\mathrm{PCa}$ is the most common noncutaneous cancer of men in the world and is a major cause of cancer-related mortality (Coleman et al. 2008). Currently, testing for this disease heavily relies on the detection of the androgen-regulated serine protease, prostate-specific antigen (PSA), in serum. The expression of PSA in men is highly specific to prostate tissue, and deregulation of androgen signaling during $\mathrm{PCa}$ development and progression can result in increased levels of PSA in the blood. Unfortunately, there are a number of problems with PSA as a diagnostic tool. First, elevated serum PSA levels are not specific to $\mathrm{PCa}$, being also associated with benign prostatic hyperplasia (BPH) and prostatitis. Indeed, $<50 \%$ of men who have undergone a biopsy in response to a PSA reading of $>4.0 \mathrm{ng} / \mathrm{ml}$ are diagnosed with PCa (Grubb et al. 2008, Schroder et al. 2009). Secondly, $\sim 15 \%$ of men with a 'negative' PSA reading (0-4 ng/ml) have $\mathrm{PCa}$ (Thompson et al. 2004, Lucia et al. 2008). Finally, and most importantly, large randomized trials in the USA and Europe have demonstrated that PSA screening contributes heavily to the overdiagnosis and overtreatment of $\mathrm{PCa}$ (Andriole et al. 2009, Schroder et al. 2009). These trials validated earlier work, suggesting that $23-44 \%$ of tumors detected by screening would have never caused symptoms in the patient's lifetime (Draisma et al. 2009).

While most men with organ-confined disease are cured by definitive treatment (surgery and/or radiation therapy), up to a quarter experience relapse within 5 years (Greene et al. 2004). The outcome for these men is poor. Risk of posttreatment recurrence is assessed using preoperative PSA levels in combination with histological grade (Gleason score) and clinical staging of the tumor. However, it is becoming increasingly evident that the performance of these parameters is unsatisfactory in terms of accurately differentiating patients with aggressive cancer possessing high metastatic potential from patients with indolent disease. This not only places patients at risk of dying from PCa but also compounds the problem of overdiagnosis and overtreatment outlined above.

With this in mind, new biomarkers of PCa that improve diagnostic and prognostic accuracy are urgently required. Prognostic biomarkers that enable differentiation of lethal from indolent forms of cancer would allow individuals to make more informed choices, such as deferring treatment of slow-growing tumors or opting for aggressive treatment of lifethreatening disease. Diagnostic biomarkers that are highly specific to $\mathrm{PCa}$ would facilitate better management of men with elevated PSA and/or a positive biopsy, as was recently proposed for urinary TMPRSS2:ERG RNA transcripts (Tomlins et al. 2011), or could contradict 'false negative' PSA readings. Finally, it is worth noting that novel biomarkers for PCa are likely to be used in other settings: for example, as indicators to monitor response to novel therapeutic strategies for castration-resistant $\mathrm{PCa}$ (CRPCa; see Attard \& de Bono (2011) for review).

A number of recent studies have highlighted the potential of serum/plasma miRNAs as novel, noninvasive biomarkers for the diagnosis and prognosis of $\mathrm{PCa}$ and for predicting response to therapy (Table 1): these are described in more detail below.

\section{Circulating miRNAs as diagnostic markers of $\mathrm{PCa}$}

In pioneering work, Mitchell et al. (2008) used a mouse $\mathrm{PCa}$ xenograft system to elegantly demonstrate that human miRNAs enter the plasma of mice. They measured a panel of PCa-associated miRNAs in the serum of healthy men $(n=25)$ and men with advanced disease $(n=25)$ and found that miR-141 was highly elevated in the cancer samples. Moreover, miR-141 was correlated with serum PSA levels and could detect individuals with advanced $\mathrm{PCa}$ with $60 \%$ sensitivity at $100 \%$ specificity. A subsequent study used a custom microarray to profile miRNAs in serum from patients with various cancer types and identified 15 miRNAs at elevated levels in the circulation of $\mathrm{PCa}$ patients (Lodes et al. 2009). However, only six PCa samples from men with significant disparities, including age, disease grades, and modes of treatment, were analyzed. Indeed, the serum miRNA profile described in this study could not discriminate between $\mathrm{PCa}$ patients and those suffering from breast, ovarian, lung, or colon cancer. 
Table 1 Studies addressing the potential of circulating miRNAs as biomarkers of prostate cancer

\begin{tabular}{|c|c|}
\hline Body fluid & Sample size \\
\hline Plasma & $\begin{array}{l}25 \text { patients (metastatic } \mathrm{PCa} \text { ), } \\
25 \text { healthy controls }\end{array}$ \\
\hline \multirow[t]{4}{*}{ Serum } & $\begin{array}{l}6 \text { patients (stages } 2-4 \mathrm{PCa} \text { ), } \\
8 \text { healthy controls }\end{array}$ \\
\hline & $\begin{array}{l}56 \text { patients (20 localized } \\
\text { PCa, } 20 \text { androgen-depen- } \\
\text { dent } \mathrm{PCa}, 10 \mathrm{CRPC}^{\mathrm{a}} \text { ), } 6 \\
\mathrm{BPH}^{\mathrm{b}} \text { controls }\end{array}$ \\
\hline & $\begin{array}{l}29 \text { patients ( } 9 \text { low risk, } 11 \\
\text { intermediate risk, } 9 \text { high } \\
\text { risk) })^{c}, 9 \text { healthy controls }\end{array}$ \\
\hline & $\begin{array}{l}\text { Profiling: } 7 \text { high-grade, } 14 \\
\text { low-grade patients. Vali- } \\
\text { dation: } 116 \text { patients (var- } \\
\text { ious grades) }\end{array}$ \\
\hline
\end{tabular}

Plasma 21 patients (metastatic $\mathrm{PCa}$ )

51 patients (18 localized $\mathrm{PCa}, 8$ local advanced, 25 metastatic), 20 healthy controls

\begin{tabular}{|c|c|}
\hline Serum & $\begin{array}{l}45 \text { patients ( } 37 \text { localized } \\
\text { PCa, } 8 \text { metastatic), } 18 \\
\text { BPH controls, } 20 \text { healthy } \\
\text { controls } \\
\text { Profiling: } 14 \text { TRAMP mice, } \\
14 \text { healthy controls. Vali- } \\
\text { dation: } 25 \text { patients (meta- } \\
\text { static CRPC), } 25 \text { healthy } \\
\text { controls }\end{array}$ \\
\hline $\begin{array}{l}\text { Plasma and } \\
\text { serum }\end{array}$ & $\begin{array}{l}\text { Profiling: } 78 \text { patients (various } \\
\text { grades, } 15 \text { with diagnosed } \\
\text { metastases), } 28 \text { healthy } \\
\text { controls. Validation: } 119 \\
\text { patients (47 recurrent after } \\
\text { RP }^{d}, 72 \text { nonrecurrent) }\end{array}$ \\
\hline
\end{tabular}

qRT-PCR (miR-21 only)

Microarray (custom) (547 miRNAs)

qRT-PCR (677 miRNAs)

qRT-PCR (667 miRNAs)

Methodology
qRT-PCR (6 miRNAs)
Microarray (custom) ( 547
miRNAs)$$
\text { qRT-PCR (667 miRNAs) }
$$

Major findings

miR-141 levels could differentiate PCa patients from healthy subjects

15 miRNAs were elevated in Lodes et al. (2009) PCa patients. However, serum miRNAs could not distinguish between different cancer types miR-21 levels elevated in CRPC patients compared with BPH. miR-21 associated with resistance to docetaxel in CRPC patients

10 miRNAs altered in $\mathrm{PCa}$ patients compared with healthy controls. $7 \mathrm{miR}$ NAs correlated with different risk groups miR-141, miR-200b, and miR-375 were elevated in serum from high-grade patients and correlated with clinicopathological parameters

miR-141 levels associated with clinical progression. miR-141 positively correlated with prostate-specific antigen

qRT-PCR (miR-21, miR-141, miR-21 and miR-221 levels and miR-221) elevated in PCa patients compared with healthy controls. miR-21, miR141, and miR-221 levels higher in metastatic vs localized disease

qRT-PCR (5 miRNAs)

miR-26a, miR-195, and let-7i Mahn et al. (2011) levels elevated in $\mathrm{PCa}$ compared with BPH samples

Microarray (Affymetrix), qRT- miR-141, miR-298, miR-346, Selth et al. (2011) PCR (609 murine miRNAs, 10 human miRNAs)

qRT-PCR (742 miRNAs)

\section{Reference}

Mitchell et al. (2008)

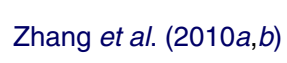

Moltzahn et al. (2011)

Brase et al. (2011)

Gonzales et al. (2011)

Yaman Agaoglu et al. (2011)

Bryant et al. (2012) and miR-375 levels

elevated in patients

12 miRNAs altered in $\mathrm{PCa}$ patients compared with healthy controls. $16 \mathrm{miR}$ NAs altered in metastatic vs localized $\mathrm{PCa}$ (including miR-141 and miR-375)

\footnotetext{
${ }^{\mathrm{a} C}$ Castration-resistant prostate cancer.

benign prostatic hyperplasia.

c'Cancer of the prostate risk assessment' score.

${ }^{\mathrm{d}}$ Radical prostatectomy.
} 
In an alternative approach designed to minimize biological variability in the discovery cohort, we analyzed serum miRNA profiles from a mouse model of PCa, transgenic adenocarcinoma of mouse prostate (TRAMP), using microarray technology (Selth et al. 2011). We validated four of the TRAMP-associated miRNAs - miR-141, miR-298, miR-346, and miR-375 - as markers of disease in sera from human patients with advanced disease. This study was the first to demonstrate that certain serum miRNAs are common between human PCa and a mouse model of the disease, highlighting the potential of such models for the discovery of novel miRNA biomarkers. The potential advantages of mouse models for these types of studies are discussed in more detail below.

More recently, Moltzahn et al. (2010) collected serum from 29 men with early-stage PCa immediately before radical prostatectomy (RP) and nine healthy men. Profiling using high-throughput (multiplexed) quantitative real-time PCR (qRT-PCR) identified ten miRNAs significantly altered in the malignant samples. Receiver operating characteristic (ROC) curves generated for individual miRNAs revealed that most of these miRNAs possessed significant diagnostic capability: for example, the area under the curve (AUC) for both miR-106a and miR-1274 was 0.928 .

In a study aimed at testing the diagnostic utility of three specific PCa-associated miRNAs, miR-21, miR141, and miR-221, Yaman Agaoglu et al. (2011) found that miR-21 and miR-221 were elevated in the plasma of men with localized cancer compared with healthy controls. Moreover, these three miRNAs were increased in samples from men with bone metastases compared with men with localized/locally advanced disease, and miR-141 could accurately distinguish between these groups (AUC $=0.755)$. Mahn et al. (2011) conducted a similar study but profiled four different PCa-associated miRNAs: miR-26a, miR-32, miR-195, and let-7i. They found that miR-26a, miR195 , and let-7i were increased in the serum of men with localized PCa compared with men with BPH, and a signature comprising all four miRNAs effectively distinguished between these groups $(\mathrm{AUC}=0.758)$. Of note, none of the candidate PCa-associated miRNAs were significantly altered in the serum of men with $\mathrm{PCa}$ compared with healthy individuals. This calls into question the utility of these particular miRNAs as markers of $\mathrm{PCa}$, although it must be noted that the healthy control samples were collected from much younger population of men.

Most recently, Bryant et al. (2012) assessed the diagnostic capacity of plasma miRNAs by high-throughput qRT-PCR profiling. Twelve miRNAs were differentially quantitated in the circulation of men with $\mathrm{PCa}$ (of diverse grade and stage) compared with healthy men, with miR-107 showing the greatest foldchange. In ROC analyses, miR-107 had an AUC of 0.62 compared with an AUC of 0.79 for PSA. Interestingly, five of the PCa-associated miRNAs found in plasma were detectable in urine, and miR-107 and miR-574-3p were present at significantly higher concentrations in men with PCa compared with healthy controls. Of note, in this cohort, the urinary levels of miR-107 and miR574-3p were more diagnostically informative than $P C A 3$ mRNA, a well-characterized urine marker of PCa (Hessels et al. 2003).

The studies described earlier suggest that circulating miRNAs may assist in the diagnosis of PCa. Further validation of these putative new markers and comparisons with current diagnostic tools in large, carefully selected cohorts that represent different clinical groups - for example, PSA- or non-PSA-screened, biopsied or not - are now warranted.

\section{Circulating miRNAs as prognostic markers of $\mathrm{PCa}$}

Three studies have investigated the prognostic potential of circulating miRNAs in PCa. Brase et al. (2011) compared serum from men with primary and metastatic cancer by multiplexed qRT-PCR to discover circulating miRNAs associated with PCa progression. This experiment identified 69 miRNAs elevated in men with systemic disease. A subset of these miRNAs was then measured in serum taken from 42 men with localized disease at the time of RP. Three miRNAs, miR-141, miR-200b, and miR-375, were elevated with increasing tumor stage and Gleason score in this validation set, suggesting that they may be indicators of high-risk cancer. Moltzahn et al. (2010) compared serum collected before RP from 29 patients with different 'cancer of the prostate risk assessment' (CAPRA) scores. A number of miRNAs, including miR-24, miR-106a, miR-451, and miR-93, were altered in malignant samples and associated with CAPRA score. Finally, a recent study identified 16 miRNAs, including miR-141, miR-200b, and miR375 , at differential levels in the plasma of men with localized $(n=55)$ or metastatic $(n=11)$ PCa (Bryant et al. 2012). The authors went on to validate the association of miR-141 and miR-375 with metastatic disease in an independent set of serum samples, although the prognostic utility of these biomarkers in men with localized disease was not assessed in this study. 
These studies suggest that serum/plasma miRNAs could be used to predict high-risk tumors and, as such, be a useful complement to the current prognostic armamentarium. In particular, the robust association of miR-141, miR-200b, and miR-375 with metastatic disease is noteworthy: these markers could potentially be applied at the time of diagnosis to identify patients with aggressive disease/micrometastases and/or to predict recurrence following primary treatment. Future studies must validate candidate prognostic miRNAs in cohorts with long-term clinical follow-up to test whether circulating miRNAs are predictive of disease progression, either following definitive treatment for putative localized disease or for men on active surveillance regimes.

\section{Using circulating miRNAs to predict treatment response in $\mathrm{PCa}$}

Zhang et al. used qRT-PCR to measure miR-21 in patients with localized PCa $(n=20)$, androgen-dependent PCa (ADPC; $n=20)$, CRPCa $(n=10)$, or BPH $(n=6)$. miR-21 levels were not significantly different between BPH, localized cancer, or ADPC with PSA < $4 \mathrm{ng} / \mathrm{ml}$ but were increased in CRPCa and ADPC with PSA $>4 \mathrm{ng} / \mathrm{ml}$. Of particular interest, levels of miR-21 were significantly higher in the four CRPCa patients who were resistant to the chemotherapeutic docetaxel (Zhang et al. 2010a). This work provided the first evidence that circulating miRNAs can predict response to a cancer treatment.

A more recent study specifically aimed to assess the utility of plasma miR-141 as a biomarker of treatment response (Gonzales et al. 2011). In 21 patients with either castration-resistant or hormone-sensitive metastatic PCa receiving a range of therapies (i.e. chemotherapy, hormone therapy, or new agents as part of clinical trials), miR-141 had a sensitivity of $78.9 \%$ and specificity of $68.8 \%$ in predicting clinical progression. This prognostic performance was similar to PSA, circulating tumor cells (CTCs), and serum lactate dehydrogenase, and miR-141 was highly correlated with these other markers. While the latter observation suggests that miR-141 may not contribute much additional prognostic information in this cohort of men, the study highlights the potential of circulating miRNAs for evaluating treatment efficacy.

\section{Specificity of circulating miRNA biomarkers}

Notwithstanding the deserved excitement surrounding the findings described above, it has been noted that no single analyte is likely to achieve the desired level of diagnostic or prognostic accuracy for PCa (Steuber et al. 2008). The evidence thus far suggests that this will also be true for circulating miRNAs. For example, many different tumor entities are associated with increased levels of circulating miR-21, including lymphoma (Lawrie et al. 2008), pancreatic cancer (Kong et al. 2011), and breast cancer (Asaga et al. 2011). Similarly, a circulating miRNA that is robustly associated with PCa, miR-141, is also elevated in plasma from patients with colon cancer (Cheng et al. 2011). With these results in mind, the application of circulating miRNAs in a clinical setting is likely to involve evaluation of a signature of multiple miRNAs rather than a single miRNA.

\section{Beyond biomarkers: the role of circulating miRNAs in $\mathrm{PCa}$}

Certain miRNAs are elevated both in the circulation of patients and in prostate tumors, suggesting that they originate from the malignant tissue and play a role in tumor development and/or progression (Mitchell et al. 2008, Brase et al. 2011, Selth et al. 2011). For example, miR-375 is a serum/plasma marker of PCa and is also consistently upregulated in tumors (Szczyrba et al. 2010, Brase et al. 2011, Selth et al. 2011, Szczyrba et al. 2011, Bryant et al. 2012). By interrogating data from the Prostate Cancer OncoGenome Project (Taylor et al. 2010), we found that the intratumoral expression of miR-375 at the time of RP can predict biochemical relapse, with high expression being associated with an unfavorable outcome (hazard ratio $=3.49$; Selth et al. 2011). Bioinformatic prediction of miR-375 targets revealed enrichment for genes involved in PCa development and progression (Selth et al. 2011). Indeed, another study found that miR-375 targets SEC23A, which encodes a putative tumor suppressor in PCa (Szczyrba et al. 2011). Further elucidation of the functions and targets of miR-375 will reveal whether targeting this miRNA is a viable therapeutic strategy.

Like miR-375, miR-141 is elevated in both the circulation of men with $\mathrm{PCa}$ and prostate tumors (Mitchell et al. 2008, Brase et al. 2011, Gonzales et al. 2011, Selth et al. 2011, Yaman Agaoglu et al. 2011, Bryant et al. 2012). miR-141 is a member of the miR200 family, which functions to repress the epithelial to mesenchymal transition (EMT) by targeting the ZEB family of transcription factors (Bracken et al. 2009). Of note, miR-141 is cotranscribed with another miR-200 family member, miR-200c, that is also elevated in malignant prostate tissue (Szczyrba et al. 2010). While EMT is known to play a key role in cancer metastasis (Nauseef \& Henry 2011), it is currently unclear why 
epithelial specific miRNAs are upregulated in primary prostate tumors. Interestingly, miR-141 was correlated with CTC concentration in one study, suggesting that CTCs may retain some epithelial characteristics (Gonzales et al. 2011). Clearly, more work is required to elucidate the function of this factor; however, the available evidence supports the hypothesis that miR141 plays an important role in cancer development and/ or progression to metastasis.

These examples suggest that miRNAs identified as circulating markers of $\mathrm{PCa}$ can be derived from the primary tumor and influence its development and progression to lethal disease. Therefore, studies aimed at identifying new noninvasive miRNA biomarkers are not only useful for their potential application in clinical settings but are also likely to provide fundamental and important insight into the biology of $\mathrm{PCa}$ and result in the identification of novel drug targets.

\section{Association between androgen signaling and circulating miRNA markers of $\mathrm{PCa}$}

The androgen receptor (AR) signaling axis plays a pivotal role in prostate carcinogenesis and progression to more advanced forms of the disease (Heinlein \& Chang 2004, Scher et al. 2004). Thus, factors regulated by or impinging on this axis are often dysregulated in $\mathrm{PCa}$, some of which may have potential as biomarkers. The classic example is PSA, which is encoded by a gene $(K L K 3)$ that is directly regulated by AR. Given that the miRNA transcriptome is profoundly affected by androgen signaling in PCa (for review, see Coppola et al. (2009)), it is not surprising that androgenic regulation of many of the circulating miRNAs described earlier has been documented (e.g. miR-141 and other miR-200 family members (Szczyrba et al. 2010, Waltering et al. 2010), miR-375 (Szczyrba et al. 2010, Waltering et al. 2010), miR-21 (Shi et al. 2007, Ribas et al. 2009, Narayanan et al. 2010), and miR-221 (Sun et al. 2009)). These observations provide important mechanistic information regarding the origins of these potential biomarkers, which may be critical for their effective clinical implementation.

While the evidence implies that circulating miRNA markers of PCa are likely to be influenced by androgen signaling, it is worth noting that the activity of this pathway is not always an informative indicator of cancer behavior or even malignancy, a concept that is perhaps best exemplified by the limitations of PSA (discussed earlier). In our opinion, putative or known links between biomarkers and cancer pathophysiology may be instructive but are unnecessary if the biomarker has robust, validated clinical utility.

\section{Methodologies and strategies for identification of circulating miRNA markers of cancer}

Isolation of miRNAs from serum and plasma is relatively straightforward. In general, most protocols use guanidinium-phenol extraction of the sample followed by either precipitation of the miRNAcontaining aqueous phase or column-based purification of miRNAs from the aqueous phase (Kroh et al. 2010, Weber et al. 2010). A number of important considerations for extracting miRNAs from blood-based fluids have been described already (Kroh et al. 2010). One issue that we would like to reiterate is the potential of contaminating cellular material, which has a higher concentration of miRNAs than plasma or serum, to confound miRNA quantitation (Kroh et al. 2010). This contamination could arise from the presence of intact blood cells in serum/plasma or lysis of these cells (hemolysis) during sampling and processing (Duttagupta et al. 2011, Kirschner et al. 2011, McDonald et al. 2011). Recent work found that an additional centrifuge step after plasma preparation efficiently removes intact blood cells and a significant fraction of contaminating cellular miRNAs (Duttagupta et al. 2011). Hemolysis, which frequently occurs at low levels during collection of serum/plasma, is a more difficult problem to circumvent. Two studies have highlighted the profound effect hemolysis can have on miRNA concentrations in blood fluids (Kirschner et al. 2011, McDonald et al. 2011). The extent of hemolysis can be estimated by the measurement of free hemoglobin and certain miRNAs (e.g. miR-15b, miR-16, and miR-451), which may be necessary to determine whether a serum/plasma sample is suitable for analysis (Kirschner et al. 2011, McDonald et al. 2011). We believe that standardization of miRNA isolation from serum/plasma and other bodily fluids, taking into account factors such as phlebotomy protocol, sample processing, and miRNA extraction methodology, is one of the most urgent requirements for preclinical experimentation and will maximize the translatability of these studies.

After purification, a general strategy for identifying cancer-associated miRNAs in the circulation is to globally profile and compare the miRNA populations from cancer samples and healthy controls (discovery) and then measure candidate miRNAs by qRT-PCR in a larger, independent cohort (validation). Profiling in the discovery phase is done, in general, using one of the three techniques: qRT-PCR, next-generation sequencing (NGS), or miRNA microarrays. The first stage of qRT-PCR profiling is a reaction in which all miRNAs 
of interest (often the entire known miRNAome) are reverse transcribed. This can be achieved by tailing the miRNA molecules and using a common RT primer (i.e. oligo-dT) or by using a pool of RT primers that are specific for each miRNA. Subsequently, miRNAs are amplified by qPCR using 96-well or 384-well miRNA arrays. A consensus protocol for analyzing miRNAs from serum or plasma using qRT-PCR is emerging, and this will likely apply to other body fluids as well (Kroh et al. 2010). NGS and microarray profiling of miRNAs are less frequently used techniques because they require more RNA and hence more starting material. A workflow to circumvent this issue by pooling RNA samples from cancer and healthy groups before Illumina NGS was recently proposed (Zen \& Zhang 2010). In this experimental strategy, validation of the NGS data by qRT-PCR is subsequently carried out at an individual patient level using separate training and testing cohorts. NGS has the benefit of being able to identify unknown RNA species that would not be amplified by qRT-PCR. This may be a significant advantage given the emerging notion that miRNA $5^{\prime}$ - and $3^{\prime}$-end structural variants, termed isomirs, are commonly expressed and have been linked to cancer (Lee et al. 2010, Ryan et al. 2010). However, pooling samples reduce the statistical power of the profiling experiment. Moreover, NGS and microarray profiling are more technically challenging for most laboratories and require extensive validation, while NGS remains expensive and labor intensive. These issues may explain why qRT-PCR-based profiling strategies, which can quantify the miRNAome from minute quantities of individual patient material, are more frequently used.

There are a number of unresolved issues relating to miRNA profiling of serum and plasma. The first is how to best normalize miRNA concentrations to account for biological and technical variability. Quantitating the amount of miRNA in body fluid specimens is often not possible because of the extremely low concentrations found in such samples. One method to overcome this issue would be to use internal reference (housekeeping) miRNAs, as is commonly done for mRNA profiling. However, there is currently no consensus on suitable small RNA reference genes in circulation (Kroh et al. 2010). A number of studies have used miR-16 for normalization purposes (Lawrie et al. 2008, Huang et al. 2010), but more recent work has found that this molecule is highly expressed in erythrocytes and that its levels in the cell-free content of blood can vary significantly due to hemolysis (Kirschner et al. 2011, McDonald et al. 2011). Our current preference is to process all samples from identical input volumes and then correct for technical variability of the RNA extraction using spiked-in control miRNAs from Caenorhabditis elegans that lack human homologs, as originally proposed by the Tewari Laboratory (Mitchell et al. 2008). Another common point of difference in studies that use qRT-PCR to analyze miRNAs in the circulation is whether or not to 'preamplify' the cDNA before real-time PCR. Commercially available preamplification reagents can be used to increase sensitivity of the qRT-PCR protocol, and we have found that this greatly increases the number of detectable miRNAs in serum from patients with PCa (L A Selth, unpublished observations). Again, the application of miRNA biomarkers in a clinical setting will require rigorous standardization of these protocols.

An alternative discovery strategy that deserves mention is to use blood fluid samples from mouse models of disease. Many cancers show significant heterogeneity at the molecular level, which is likely to be reflected in the circulating miRNA fingerprints associated with that pathology. Genetically engineered mouse models of human cancers exhibit greatly reduced biological and nonbiological heterogeneity by providing defined stages of tumor development, genetic uniformity, homogenized breeding and environmental conditions, controllable health status, and standardized sampling (Kuick et al. 2007). In a recent study, we used the TRAMP model of PCa in the discovery (profiling) phase and then validated a subset of circulating miRNAs in human patient samples (Selth et al. 2011). Other recent studies have further highlighted the utility of mouse models of disease for the discovery of blood-derived miRNA markers (Cacchiarelli et al. 2011, LaConti et al. 2011, Mizuno et al. 2011, Starkey Lewis et al. 2011). We believe that animal models will be increasingly used for this purpose in the coming years in order to fast track the development of novel clinical biomarkers and therapeutics.

\section{Can circulating miRNAs act non-cell-autonomously?}

When searching for circulating miRNAs that demarcate disease and could have important clinical applications, one could be forgiven for overlooking a simple question: what is the function of these molecules? Are they simply the remnants of dead cells that have accumulated in the blood? Or do miRNAs secreted into bodily fluids mediate intercellular gene regulation? This latter hypothesis has precedence in the plant kingdom: the movement 
of miRNA-165/166 communicates radial position information between cells in the root via modulation of target gene expression, a signaling mechanism that is required for normal root development (Carlsbecker et al. 2010).

If circulating miRNAs have an intrinsic capacity to function non-cell-autonomously, mechanisms should exist to protect them from degradation in body fluids (Cortez et al. 2011). Indeed, miRNAs in serum and plasma are resistant to ribonucleases and severe physicochemical conditions such as boiling, extended storage, freeze-thawing, and extreme $\mathrm{pH}$ levels (Chen et al. 2008, Mitchell et al. 2008). Emerging evidence indicates that this stability is related to sequestration of extracellular miRNAs in various types of protective structures. First, miRNAs can be encapsulated in lipid vesicles, including exosomes (Valadi et al. 2007, Kosaka et al. 2010, Kuwabara et al. 2011), microvesicles (Skog et al. 2008, Zhang et al. 2010b), and apoptotic bodies (Zernecke et al. 2009). Secondly, miRNAs can be bound by RNA-binding proteins, including nucleophosmin 1 (NPM1; Wang et al. 2010) and argonaute 2 (AGO2 (EIF2C2); Arroyo et al. 2011). This latter finding is particularly interesting: $\mathrm{AGO} 2$ is part of the RISC complex and therefore a key mediator of target mRNA silencing. Thus, if AGO2:miRNA complexes are efficiently taken up by recipient cells, they could rapidly and effectively transduce a genesilencing signal. Finally, a unique population of miRNAs in the blood is associated with high-density lipoprotein (HDL; Vickers et al. 2011). Collectively, these data provide evidence for structurally diverse extracellular miRNA-containing entities, which likely underlie the remarkable stability of miRNAs in the circulation. Moreover, they suggest that targeted enrichment of these entities may improve the utility of miRNAs as biomarkers. For example, isolation of organ- or tissue-specific exosomes using protein surface markers could enrich for a cancer-specific miRNA population, as has been described for ovarian tumor-derived exosomes (Taylor \& Gercel-Taylor 2008).

Non-cell-autonomous/signaling functions of miRNAs would likely be associated with active and selective export of these molecules, rather than passive release in response to, for example, tissue damage. A number of observations provide evidence for selective export of miRNAs into circulating fluids. First, small RNAs in the blood are highly enriched for miRNA species (Chen et al. 2008). Secondly, the levels of miRNAs in circulation vary widely according to gender (Duttagupta et al. 2011), age, physiological events (e.g. pregnancy (Gilad et al. 2008)), and environmental factors (Cortez et al. 2011). As an aside, this observation indicates that control samples will need to be carefully selected in biomarker discovery studies (Cortez et al. 2011). Thirdly, there is evidence for selective secretion of miRNAs in exosomes. For example, the bulk of miR-1246 and miR-451 was found to be released by breast cancer MCF7 cells in exosomes, but these miRNAs were retained by a nonmalignant mammary epithelial cell

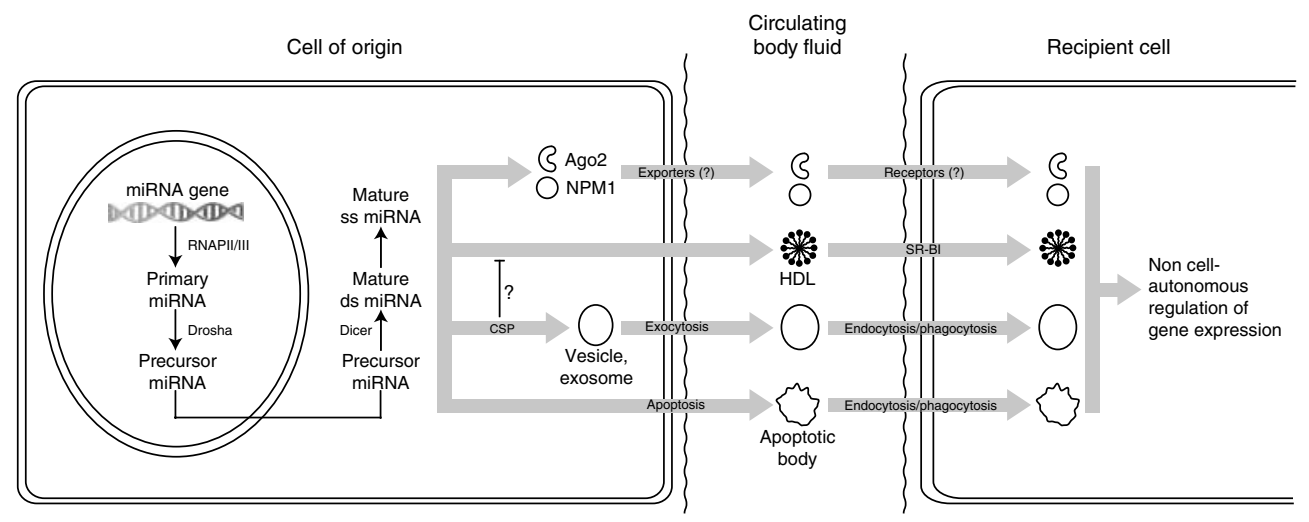

Figure 1 Potential transport mechanisms underlying noncell-autonomous action of miRNAs. miRNAs are transcribed in the nucleus and processed to mature forms in the cytoplasm. Subsequently, miRNAs could be released into circulating body fluids as nucleoprotein complexes (i.e. bound to AGO2 or NPM1), in microvesicles or in apoptotic bodies. Alternatively, 'free' miRNAs could penetrate the cell membrane or be released by necrosis/apoptosis and enter the circulation where they may associate with highdensity lipoprotein (HDL), which would protect them from extracellular nuclease attack. The ceramide secretory pathway (CSP), which triggers cellular export of miRNAs in exosomes, may repress export to HDL. Circulating miRNA complexes could be delivered to recipient cells by endocytosis, phagocytosis, specific receptors (e.g. scavenger receptor class B member 1 (SR-BI (SCARB1)) may import HDL:miRNA complexes), or other as-yet-unknown receptors, where the miRNAs could regulate the expression of target genes. See main text for references. 
line (Pigati et al. 2010). Similarly, a subset of miRNAs is specifically released in exosomes from heart cells in response to myocardial infarction (Kuwabara et al. 2011). Finally, recent evidence suggests that exosomal miRNA complexes are actively released in a process involving ceramide-dependent secretory machinery, with an enzyme involved in ceramide synthesis, neutral sphingomyelinase 2 (nSMase2 (SMPD3)), seemingly playing a key role (Kosaka et al. 2010). Interestingly, NSMASE2 and the ceramide machinery appear to repress the export of miRNAs to HDL, suggesting that the exosomal and HDL pathways have distinct and opposing roles in the export of miRNAs (Vickers et al. 2011).

Thus, the stability of miRNAs in circulation and evidence for their selective release or export support the idea that cells secrete functional miRNAs (Fig. 1). More direct evidence for this idea has recently been provided by in vitro studies demonstrating that exosome-, microvesicle-, apoptotic body-, or HDLassociated miRNA can regulate expression of both endogenous target genes and exogenous reporter constructs in recipient cells (Valadi et al. 2007, Skog et al. 2008, Yuan et al. 2009, Zernecke et al. 2009, Pegtel et al. 2010). The mechanisms of miRNA export and import remain to be fully elucidated, and it must be noted that noncell-autonomous actions of miRNAs in human pathology or normal physiology are yet to be demonstrated in vivo. However, the evidence outlined here strongly supports the existence of 'hormomirs' that are released by donor cells, enter the circulation, and regulate gene expression in target cells, tissues, and organs (Fig. 1), a paradigm originally hypothesized by Cortez et al. (2011). In normal physiology, hormomirs may be key regulators of homeostasis. By contrast, tumor cells could deliver miRNAs to the surrounding microenvironment to facilitate growth and invasion (Skog et al. 2008), a hypothesis that warrants further experimental attention given the potential of targeting circulating miRNAs therapeutically.

\section{Concluding remarks: future work and challenges}

The identification of miRNAs in body fluids, including the blood, has triggered considerable excitement in the biomarker field. We believe that this excitement is well founded: based on their stability and relative ease of detection, circulating miRNAs may become one of the most important pieces in the personalized medicine armory. However, their utility has so far been limited by conflicting data between studies, probably due to inconsistency in methodology, the lack of suitable reference genes for normalization, small sample sizes, and differences in fluid and miRNA preparation (Cortez et al. 2011). Standardized methodologies and larger sample sets are now vital to more effectively explore the clinical potential of circulating miRNAs. Furthermore, it is vital to thoroughly characterize how circulating miRNAomes, which appear to be quite dynamic, change in response to age, normal physiological conditions, and extrinsic factors. We believe that these challenges will be rapidly overcome and that noninvasive detection of circulating miRNAs will soon be an important aspect of detection and management of many diseases, including PCa. Indeed, a miRNA-based diagnostic test for pancreatic ductal adenocarcinoma was recently launched by Asuragen (Lee et al. 2007, Szafranska et al. 2008, Park et al. 2011, SzafranskaSchwarzbach et al. 2011).

Finally, it is worth noting that at least a fraction of the circulating miRNA population may be acting as 'hormomirs' to transduce gene modulation signals and thereby systemically influence normal homeostasis and disease pathology. Thus, in addition to their potential as biomarkers, circulating miRNAs could represent a new class of molecules that are amenable to manipulation for therapeutic purposes.

\section{Declaration of interest}

The authors declare that there is no conflict of interest that could be perceived as prejudicing the impartiality of the research reported.

\section{Funding}

The authors would like to acknowledge the following funding sources: the Prostate Cancer Foundation of Australia (to L A S, ID: YI0810), Cancer Australia (ID: 1012337), and the National Health and Medical Research Council (ID: 627185). L A S held a Freemasons Foundation Centre for Men's Health Research Fellowship while this article was in preparation and L M B holds a Senior Research Fellowship from the Cancer Council of South Australia.

\section{Acknowledgements}

The authors would like to thank Joanna Gillis and Scott Townley for expert discussion and technical assistance.

\section{References}

Andriole GL, Crawford ED, Grubb RL III, Buys SS, Chia D, Church TR, Fouad MN, Gelmann EP, Kvale PA, Reding DJ et al. 2009 Mortality results from a randomized prostate-cancer screening trial. New England Journal of Medicine 360 1310-1319. (doi:10.1056/NEJMoa0810696) 
Arroyo JD, Chevillet JR, Kroh EM, Ruf IK, Pritchard CC, Gibson DF, Mitchell PS, Bennett CF, PogosovaAgadjanyan EL, Stirewalt DL et al. 2011 Argonaute2 complexes carry a population of circulating microRNAs independent of vesicles in human plasma. PNAS $\mathbf{1 0 8}$ 5003-5008. (doi:10.1073/pnas.1019055108)

Asaga S, Kuo C, Nguyen T, Terpenning M, Giuliano AE \& Hoon DS 2011 Direct serum assay for microRNA-21 concentrations in early and advanced breast cancer. Clinical Chemistry 57 84-91. (doi:10.1373/clinchem. 2010.151845)

Attard G \& de Bono JS 2011 Translating scientific advancement into clinical benefit for castration-resistant prostate cancer patients. Clinical Cancer Research 17 3867-3875. (doi:10.1158/1078-0432.CCR-11-0943)

Bernstein E, Kim SY, Carmell MA, Murchison EP, Alcorn H, Li MZ, Mills AA, Elledge SJ, Anderson KV \& Hannon GJ 2003 Dicer is essential for mouse development. Nature Genetics 35 215-217. (doi:10.1038/ng1253)

Blitzblau RC \& Weidhaas JB 2010 MicroRNA binding-site polymorphisms as potential biomarkers of cancer risk. Molecular Diagnosis \& Therapy 14 335-342. (doi:10.2165/11587600-000000000-00000)

Boyerinas B, Park SM, Hau A, Murmann AE \& Peter ME 2010 The role of let-7 in cell differentiation and cancer. Endocrine-Related Cancer 17 F19-F36. (doi:10.1677/ ERC-09-0184)

Bracken CP, Gregory PA, Khew-Goodall Y \& Goodall GJ 2009 The role of microRNAs in metastasis and epithelialmesenchymal transition. Cellular and Molecular Life Sciences 66 1682-1699. (doi:10.1007/s00018-009-8750-1)

Brase JC, Wuttig D, Kuner R \& Sultmann H 2010 Serum microRNAs as non-invasive biomarkers for cancer. Molecular Cancer 9 306. (doi:10.1186/1476-4598-9-306)

Brase JC, Johannes M, Schlomm T, Falth M, Haese A, Steuber T, Beissbarth T, Kuner R \& Sultmann H 2011 Circulating miRNAs are correlated with tumor progression in prostate cancer. International Journal of Cancer 128 608-616. (doi:10.1002/ijc.25376)

Bryant RJ, Pawlowski T, Catto JW, Marsden G, Vessella RL, Rhees B, Kuslich C, Visakorpi T \& Hamdy FC 2012 Changes in circulating microRNA levels associated with prostate cancer. British Journal of Cancer 106 768-774. (doi:10.1038/bjc.2011.595)

Bushati N \& Cohen SM 2007 microRNA functions. Annual Review of Cell and Developmental Biology 23 175-205. (doi:10.1146/annurev.cellbio.23.090506.123406)

Cacchiarelli D, Legnini I, Martone J, Cazzella V, D'Amico A, Bertini E \& Bozzoni I 2011 miRNAs as serum biomarkers for Duchenne muscular dystrophy. EMBO Molecular Medicine 3 258-265. (doi:10.1002/emmm.201100133)

Calin GA \& Croce CM 2006 MicroRNA signatures in human cancers. Nature Reviews. Cancer 6 857-866. (doi:10.1038/nrc1997)

Calin GA, Sevignani C, Dumitru CD, Hyslop T, Noch E, Yendamuri S, Shimizu M, Rattan S, Bullrich F, Negrini M et al. 2004 Human microRNA genes are frequently located at fragile sites and genomic regions involved in cancers. PNAS 101 2999-3004. (doi:10.1073/pnas. 0307323101)

Carlsbecker A, Lee JY, Roberts CJ, Dettmer J, Lehesranta S, Zhou J, Lindgren O, Moreno-Risueno MA, Vaten A, Thitamadee $\mathrm{S}$ et al. 2010 Cell signalling by microRNA165/6 directs gene dose-dependent root cell fate. Nature 465 316-321. (doi:10.1038/nature08977)

Chen X, Ba Y, Ma L, Cai X, Yin Y, Wang K, Guo J, Zhang Y, Chen J, Guo X et al. 2008 Characterization of microRNAs in serum: a novel class of biomarkers for diagnosis of cancer and other diseases. Cell Research 18 997-1006. (doi:10.1038/cr.2008.282)

Cheng H, Zhang L, Cogdell DE, Zheng H, Schetter AJ, Nykter M, Harris CC, Chen K, Hamilton SR \& Zhang W 2011 Circulating plasma MiR-141 is a novel biomarker for metastatic colon cancer and predicts poor prognosis. PLOS ONE 6 e17745. (doi:10.1371/journal.pone. 0017745)

Chim SS, Shing TK, Hung EC, Leung TY, Lau TK, Chiu RW \& Lo YM 2008 Detection and characterization of placental microRNAs in maternal plasma. Clinical Chemistry 54 482-490. (doi:10.1373/clinchem.2007. 097972)

Chin LJ, Ratner E, Leng S, Zhai R, Nallur S, Babar I, Muller RU, Straka E, Su L, Burki EA et al. 2008 A SNP in a let-7 microRNA complementary site in the KRAS $3^{\prime}$ untranslated region increases non-small cell lung cancer risk. Cancer Research 68 8535-8540. (doi:10.1158/ 0008-5472.CAN-08-2129)

Coleman MP, Quaresma M, Berrino F, Lutz JM, De Angelis R, Capocaccia R, Baili P, Rachet B, Gatta G, Hakulinen $\mathrm{T}$ et al. 2008 Cancer survival in five continents: a worldwide population-based study (CONCORD). Lancet Oncology 9 730-756. (doi:10.1016/S1470-2045(08)70179-7)

Coppola V, De Maria R \& Bonci D 2009 MicroRNAs and prostate cancer. Endocrine-Related Cancer 17 F1-F17. (doi:10.1677/ERC-09-0172)

Cortez MA, Bueso-Ramos C, Ferdin J, Lopez-Berestein G, Sood AK \& Calin GA 2011 MicroRNAs in body fluids the mix of hormones and biomarkers. Nature Reviews. Clinical Oncology 8 467-477. (doi:10.1038/nrclinonc. 2011.76)

Croce CM 2009 Causes and consequences of microRNA dysregulation in cancer. Nature Reviews. Genetics 10 704-714. (doi:10.1038/nrg2634)

Djuranovic S, Nahvi A \& Green R 2011 A parsimonious model for gene regulation by miRNAs. Science $\mathbf{3 3 1}$ 550-553. (doi:10.1126/science.1191138)

Draisma G, Etzioni R, Tsodikov A, Mariotto A, Wever E, Gulati R, Feuer E \& de Koning H 2009 Lead time and overdiagnosis in prostate-specific antigen screening: importance of methods and context. Journal of the National Cancer Institute 101 374-383. (doi:10.1093/ jnci/djp001) 
Duttagupta R, Jiang R, Gollub J, Getts RC \& Jones KW 2011 Impact of cellular miRNAs on circulating miRNA biomarker signatures. PLOS ONE 6 e20769. (doi:10.1371/ journal.pone.0020769)

Friedman RC, Farh KK, Burge CB \& Bartel DP 2009 Most mammalian mRNAs are conserved targets of microRNAs. Genome Research 19 92-105. (doi:10.1101/ gr.082701.108)

Gilad S, Meiri E, Yogev Y, Benjamin S, Lebanony D, Yerushalmi N, Benjamin H, Kushnir M, Cholakh H, Melamed N et al. 2008 Serum microRNAs are promising novel biomarkers. PLOS ONE 3 e3148. (doi:10.1371/ journal.pone.0003148)

Gonzales JC, Fink LM, Goodman OB Jr, Symanowski JT, Vogelzang NJ \& Ward DC 2011 Comparison of circulating microRNA 141 to circulating tumor cells, lactate dehydrogenase, and prostate-specific antigen for determining treatment response in patients with metastatic prostate cancer. Clinical Genitourinary Cancer 9 39-45. (doi:10.1016/j.clgc.2011.05.008)

Greene KL, Meng MV, Elkin EP, Cooperberg MR, Pasta DJ, Kattan MW, Wallace K \& Carroll PR 2004 Validation of the Kattan preoperative nomogram for prostate cancer recurrence using a community based cohort: results from cancer of the prostate strategic urological research endeavor (capsure). Journal of Urology 171 2255-2259. (doi:10.1097/01.ju.0000127733.01845.57)

Grubb RL III, Pinsky PF, Greenlee RT, Izmirlian G, Miller AB, Hickey TP, Riley TL, Mabie JE, Levin DL, Chia D et al. 2008 Prostate cancer screening in the prostate, lung, colorectal and ovarian cancer screening trial: update on findings from the initial four rounds of screening in a randomized trial. BJU International 102 1524-1530. (doi:10.1111/j.1464-410X.2008.08214.x)

Hanke M, Hoefig K, Merz H, Feller AC, Kausch I, Jocham D, Warnecke JM \& Sczakiel G 2009 A robust methodology to study urine microRNA as tumor marker: microRNA126 and microRNA-182 are related to urinary bladder cancer. Urologic Oncology 28 655-661. (doi:10.1016/j. urolonc.2009.01.027)

Hanson EK, Lubenow H \& Ballantyne J 2009 Identification of forensically relevant body fluids using a panel of differentially expressed microRNAs. Analytical Biochemistry 387 303-314. (doi:10.1016/j.ab.2009.01.037)

Heinlein CA \& Chang C 2004 Androgen receptor in prostate cancer. Endocrine Reviews 25 276-308. (doi:10.1210/er. 2002-0032)

Hessels D, Klein Gunnewiek JM, van Oort I, Karthaus HF, van Leenders GJ, van Balken B, Kiemeney LA, Witjes JA \& Schalken JA 2003 DD3(PCA3)-based molecular urine analysis for the diagnosis of prostate cancer. European Urology 44 8-15 (discussion 15-16). (doi:10.1016/ S0302-2838(03)00201-X)

Huang Z, Huang D, Ni S, Peng Z, Sheng W \& Du X 2010 Plasma microRNAs are promising novel biomarkers for early detection of colorectal cancer. International Journal of Cancer 127 118-126. (doi:10.1002/ijc.25007)
Kirschner MB, Kao SC, Edelman JJ, Armstrong NJ, Vallely MP, van Zandwijk N \& Reid G 2011 Haemolysis during sample preparation alters microRNA content of plasma. PLOS ONE 6 e24145. (doi:10.1371/journal.pone. 0024145)

Kong X, Du Y, Wang G, Gao J, Gong Y, Li L, Zhang Z, Zhu J, Jing Q, Qin Y et al. 2011 Detection of differentially expressed microRNAs in serum of pancreatic ductal adenocarcinoma patients: miR-196a could be a potential marker for poor prognosis. Digestive Diseases and Sciences 56 602-609. (doi:10.1007/s10620-010-1285-3)

Kosaka N, Iguchi H, Yoshioka Y, Takeshita F, Matsuki Y \& Ochiya T 2010 Secretory mechanisms and intercellular transfer of microRNAs in living cells. Journal of Biological Chemistry 285 17442-17452. (doi:10.1074/ jbc.M110.107821)

Koturbash I, Zemp FJ, Pogribny I \& Kovalchuk O 2010 Small molecules with big effects: the role of the microRNAome in cancer and carcinogenesis. Mutation Research $\mathbf{7 2 2}$ 94-105. (doi:10.1016/j.mrgentox.2010.05.006)

Kozomara A \& Griffiths-Jones S 2010 miRBase: integrating microRNA annotation and deep-sequencing data. Nucleic Acids Research 39 D152-D157. (doi:10.1093/nar/ gkq1027)

Kroh EM, Parkin RK, Mitchell PS \& Tewari M 2010 Analysis of circulating microRNA biomarkers in plasma and serum using quantitative reverse transcription-PCR (qRT-PCR). Methods 50 298-301. (doi:10.1016/j.ymeth. 2010.01.032)

Kuick R, Misek DE, Monsma DJ, Webb CP, Wang H, Peterson KJ, Pisano M, Omenn GS \& Hanash SM 2007 Discovery of cancer biomarkers through the use of mouse models. Cancer Letters 249 40-48. (doi:10.1016/j.canlet. 2006.12.032)

Kuwabara Y, Ono K, Horie T, Nishi H, Nagao K, Kinoshita M, Watanabe S, Baba O, Kojima Y, Shizuta S et al. 2011 Increased microRNA-1 and microRNA-133a levels in serum of patients with cardiovascular disease indicate myocardial damage. Circulation. Cardiovascular Genetics 4 446-454. (doi:10.1161/CIRCGENETICS.110. 958975)

LaConti JJ, Shivapurkar N, Preet A, Deslattes Mays A, Peran I, Kim SE, Marshall JL, Riegel AT \& Wellstein A 2011 Tissue and serum microRNAs in the $\operatorname{Kras}(\mathrm{G} 12 \mathrm{D})$ transgenic animal model and in patients with pancreatic cancer. PLoS ONE 6 e20687. (doi:10.1371/journal.pone. 0020687)

Landgraf P, Rusu M, Sheridan R, Sewer A, Iovino N, Aravin A, Pfeffer S, Rice A, Kamphorst AO, Landthaler M et al. 2007 A mammalian microRNA expression atlas based on small RNA library sequencing. Cell 129 1401-1414. (doi:10.1016/j.cell.2007.04.040)

Lawrie CH, Gal S, Dunlop HM, Pushkaran B, Liggins AP, Pulford K, Banham AH, Pezzella F, Boultwood J, Wainscoat JS et al. 2008 Detection of elevated levels of tumour-associated microRNAs in serum of patients with 
diffuse large B-cell lymphoma. British Journal of Haematology 141 672-675. (doi:10.1111/j.1365-2141. 2008.07077.x)

Lee EJ, Gusev Y, Jiang J, Nuovo GJ, Lerner MR, Frankel WL, Morgan DL, Postier RG, Brackett DJ \& Schmittgen TD 2007 Expression profiling identifies microRNA signature in pancreatic cancer. International Journal of Cancer 120 1046-1054. (doi:10.1002/ijc.22394)

Lee LW, Zhang S, Etheridge A, Ma L, Martin D, Galas D \& Wang K 2010 Complexity of the microRNA repertoire revealed by next-generation sequencing. RNA 16 2170-2180. (doi:10.1261/rna.2225110)

Li J, Wang Y, Yu W, Chen J \& Luo J 2011 Expression of serum miR-221 in human hepatocellular carcinoma and its prognostic significance. Biochemical and Biophysical Research Communications 406 70-73. (doi:10.1016/j. bbrc.2011.01.111)

Liu R, Zhang C, Hu Z, Li G, Wang C, Yang C, Huang D, Chen X, Zhang H, Zhuang R et al. 2010 A five-microRNA signature identified from genome-wide serum microRNA expression profiling serves as a fingerprint for gastric cancer diagnosis. European Journal of Cancer 47 784-791. (doi:10.1016/j.ejca.2010.10.025)

Liu XG, Zhu WY, Huang YY, Ma LN, Zhou SQ, Wang YK, Zeng F, Zhou JH \& Zhang YK 2011 High expression of serum miR-21 and tumor miR-200c associated with poor prognosis in patients with lung cancer. Medical Oncology 19 618-626. (doi:10.1007/s12032-011-9923-y)

Lodes MJ, Caraballo M, Suciu D, Munro S, Kumar A \& Anderson B 2009 Detection of cancer with serum miRNAs on an oligonucleotide microarray. PLOS ONE 4 e6229. (doi:10.1371/journal.pone.0006229)

Lu J, Getz G, Miska EA, Alvarez-Saavedra E, Lamb J, Peck D, Sweet-Cordero A, Ebert BL, Mak RH, Ferrando AA et al. 2005 MicroRNA expression profiles classify human cancers. Nature 435 834-838. (doi:10.1038/nature03702)

Lucia MS, Darke AK, Goodman PJ, La Rosa FG, Parnes HL, Ford LG, Coltman CA Jr \& Thompson IM 2008 Pathologic characteristics of cancers detected in The Prostate Cancer Prevention Trial: implications for prostate cancer detection and chemoprevention. Cancer Prevention Research 1 167-173. (doi:10.1158/19406207.CAPR-08-0078)

Mahn R, Heukamp LC, Rogenhofer S, von Ruecker A, Muller SC \& Ellinger J 2011 Circulating microRNAs (miRNA) in serum of patients with prostate cancer. Urology 77 1265.e9-1265.e16. (doi:10.1016/j.urology.2011.01.020)

McDonald JS, Milosevic D, Reddi HV, Grebe SK \& Algeciras-Schimnich A 2011 Analysis of circulating microRNA: preanalytical and analytical challenges. Clinical Chemistry 57 833-840. (doi:10.1373/clinchem. 2010.157198)

Meng F, Henson R, Wehbe-Janek H, Ghoshal K, Jacob ST \& Patel T 2007 MicroRNA-21 regulates expression of the PTEN tumor suppressor gene in human hepatocellular cancer. Gastroenterology 133 647-658. (doi:10.1053/j. gastro.2007.05.022)
Mitchell PS, Parkin RK, Kroh EM, Fritz BR, Wyman SK, Pogosova-Agadjanyan EL, Peterson A, Noteboom J, O'Briant KC, Allen A et al. 2008 Circulating microRNAs as stable blood-based markers for cancer detection. PNAS 105 10513-10518. (doi:10.1073/pnas.0804549105)

Mizuno H, Nakamura A, Aoki Y, Ito N, Kishi S, Yamamoto K, Sekiguchi M, Takeda S \& Hashido K 2011

Identification of muscle-specific microRNAs in serum of muscular dystrophy animal models: promising novel blood-based markers for muscular dystrophy. PLoS ONE 6 e18388. (doi:10.1371/journal.pone.0018388)

Moltzahn F, Olshen AB, Baehner L, Peek A, Fong L, Stoppler H, Simko J, Hilton JF, Carroll P \& Blelloch R 2011 Microfluidic-based multiplex qRT-PCR identifies diagnostic and prognostic microRNA signatures in the sera of prostate cancer patients. Cancer Research 71 550-560. (doi:10.1158/0008-5472.CAN-10-1229)

Narayanan R, Jiang J, Gusev Y, Jones A, Kearbey JD, Miller DD, Schmittgen TD \& Dalton JT 2010 MicroRNAs are mediators of androgen action in prostate and muscle. PLoS ONE 5 e13637. (doi:10.1371/journal.pone. 0013637)

Nauseef JT \& Henry MD 2011 Epithelial-to-mesenchymal transition in prostate cancer: paradigm or puzzle? Nature Reviews. Urology 8 428-439. (doi:10.1038/nrurol. 2011.85)

Pan X, Wang ZX \& Wang R 2011 MicroRNA-21: a novel therapeutic target in human cancer. Cancer Biology \& Therapy 10 1224-1232. (doi:10.4161/cbt.10.12.14252)

Park NJ, Zhou H, Elashoff D, Henson BS, Kastratovic DA, Abemayor E \& Wong DT 2009 Salivary microRNA: discovery, characterization, and clinical utility for oral cancer detection. Clinical Cancer Research $\mathbf{1 5}$ 5473-5477. (doi:10.1158/1078-0432.CCR-09-0736)

Park JK, Henry JC, Jiang J, Esau C, Gusev Y, Lerner MR, Postier RG, Brackett DJ \& Schmittgen TD 2011 miR-132 and miR-212 are increased in pancreatic cancer and target the retinoblastoma tumor suppressor. Biochemical and Biophysical Research Communications 406 518-523. (doi:10.1016/j.bbrc.2011.02.065)

Pegtel DM, Cosmopoulos K, Thorley-Lawson DA, van Eijndhoven MA, Hopmans ES, Lindenberg JL, de Gruijl TD, Wurdinger T \& Middeldorp JM 2010 Functional delivery of viral miRNAs via exosomes. PNAS 107 6328-6333. (doi:10.1073/pnas.0914843107)

Peter ME 2009 Let-7 and miR-200 microRNAs: guardians against pluripotency and cancer progression. Cell Cycle $\mathbf{8}$ 843-852. (doi:10.4161/cc.8.6.7907)

Pigati L, Yaddanapudi SC, Iyengar R, Kim DJ, Hearn SA, Danforth D, Hastings ML \& Duelli DM 2010 Selective release of microRNA species from normal and malignant mammary epithelial cells. PLoS ONE 5 e13515. (doi:10. 1371/journal.pone.0013515)

Pu XX, Huang GL, Guo HQ, Guo CC, Li H, Ye S, Ling S, Jiang L, Tian Y \& Lin TY 2010 Circulating miR-221 directly amplified from plasma is a potential diagnostic and prognostic marker of colorectal cancer and is 
correlated with p53 expression. Journal of Gastroenterology and Hepatology 25 1674-1680. (doi:10.1111/j. 1440-1746.2010.06417.x)

Ribas J, Ni X, Haffner M, Wentzel EA, Salmasi AH, Chowdhury WH, Kudrolli TA, Yegnasubramanian S, Luo J, Rodriguez R et al. 2009 miR-21: an androgen receptor-regulated microRNA that promotes hormonedependent and hormone-independent prostate cancer growth. Cancer Research 69 7165-7169. (doi:10.1158/ 0008-5472.CAN-09-1448)

Rosenfeld N, Aharonov R, Meiri E, Rosenwald S, Spector Y, Zepeniuk M, Benjamin H, Shabes N, Tabak S, Levy A et al. 2008 MicroRNAs accurately identify cancer tissue origin. Nature Biotechnology 26 462-469. (doi:10.1038/nbt1392)

Rosenwald S, Gilad S, Benjamin S, Lebanony D, Dromi N, Faerman A, Benjamin H, Tamir R, Ezagouri M, Goren E et al. 2010 Validation of a microRNA-based qRT-PCR test for accurate identification of tumor tissue origin. Modern Pathology 23 814-823. (doi:10.1038/modpathol.2010.57)

Roth C, Rack B, Muller V, Janni W, Pantel K \& Schwarzenbach H 2010 Circulating microRNAs as blood-based markers for patients with primary and metastatic breast cancer. Breast Cancer Research 12 R90. (doi:10.1186/bcr2766)

Ryan BM, Robles AI \& Harris CC 2010 Genetic variation in microRNA networks: the implications for cancer research. Nature Reviews. Cancer 10 389-402. (doi:10.1038/nrc2867)

Schaefer A, Stephan C, Busch J, Yousef GM \& Jung K 2010 Diagnostic, prognostic and therapeutic implications of microRNAs in urologic tumors. Nature Reviews. Urology 7 286-297. (doi:10.1038/nrurol.2010.45)

Scher HI, Buchanan G, Gerald W, Butler LM \& Tilley WD 2004 Targeting the androgen receptor: improving outcomes for castration-resistant prostate cancer. EndocrineRelated Cancer 11 459-476. (doi:10.1677/erc.1.00525)

Schroder FH, Hugosson J, Roobol MJ, Tammela TL, Ciatto S, Nelen V, Kwiatkowski M, Lujan M, Lilja H, Zappa M et al. 2009 Screening and prostate-cancer mortality in a randomized European study. New England Journal of Medicine 360 1320-1328. (doi:10.1056/ NEJMoa0810084)

Selth LA, Townley S, Gillis JL, Ochnik AM, Murti K, Macfarlane RJ, Chi KN, Marshall VR, Tilley WD \& Butler LM 2011 Discovery of circulating microRNAs associated with human prostate cancer using a mouse model of disease. International Journal of Cancer 131 652-661. (doi:10.1002/ijc.26405)

Shi XB, Xue L, Yang J, Ma AH, Zhao J, Xu M, Tepper CG, Evans CP, Kung HJ \& deVere White RW 2007 An androgen-regulated miRNA suppresses Bak1 expression and induces androgen-independent growth of prostate cancer cells. PNAS 104 19983-19988. (doi:10.1073/pnas. 0706641104)

Skog J, Wurdinger T, van Rijn S, Meijer DH, Gainche L, Sena-Esteves M, Curry WT Jr, Carter BS, Krichevsky
AM \& Breakefield XO 2008 Glioblastoma microvesicles transport RNA and proteins that promote tumour growth and provide diagnostic biomarkers. Nature Cell Biology 10 1470-1476. (doi:10.1038/ncb1800)

Starkey Lewis PJ, Dear J, Platt V, Simpson KJ, Craig DG, Antoine DJ, French NS, Dhaun N, Webb DJ, Costello EM et al. 2011 Circulating microRNAs as potential markers of human drug-induced liver injury. Hepatology 54 1767-1776. (doi:10.1002/hep.24538)

Steuber T, O’Brien MF \& Lilja H 2008 Serum markers for prostate cancer: a rational approach to the literature. European Urology 54 31-40. (doi:10.1016/j.eururo.2008. 01.034)

Sun T, Wang Q, Balk S, Brown M, Lee GS \& Kantoff P 2009 The role of microRNA-221 and microRNA-222 in androgen-independent prostate cancer cell lines. Cancer Research 69 3356-3363. (doi:10.1158/0008-5472.CAN08-4112)

Szafranska AE, Doleshal M, Edmunds HS, Gordon S, Luttges J, Munding JB, Barth RJ Jr, Gutmann EJ, Suriawinata AA, Marc Pipas J et al. 2008 Analysis of microRNAs in pancreatic fine-needle aspirates can classify benign and malignant tissues. Clinical Chemistry 54 1716-1724. (doi:10.1373/clinchem.2008.109603)

Szafranska-Schwarzbach AE, Adai AT, Lee LS, Conwell DL \& Andruss BF 2011 Development of a miRNA-based diagnostic assay for pancreatic ductal adenocarcinoma. Expert Review of Molecular Diagnostics 11 249-257. (doi:10.1586/erm.11.10)

Szczyrba J, Loprich E, Wach S, Jung V, Unteregger G, Barth S, Grobholz R, Wieland W, Stohr R, Hartmann A et al. 2010 The microRNA profile of prostate carcinoma obtained by deep sequencing. Molecular Cancer Research 8 529-538. (doi:10.1158/1541-7786.MCR-09-0443)

Szczyrba J, Nolte E, Wach S, Kremmer E, Stohr R, Hartmann A, Wieland W, Wullich B \& Grasser FA 2011 Downregulation of Sec23A protein by miRNA375 in prostate carcinoma. Molecular Cancer Research 9 791-800. (doi:10.1158/1541-7786.MCR-10-0573)

Tam W 2008 The emergent role of microRNAs in molecular diagnostics of cancer. Journal of Molecular Diagnostics 10 411-414. (doi:10.2353/jmoldx.2008.080067)

Taylor DD \& Gercel-Taylor C 2008 MicroRNA signatures of tumor-derived exosomes as diagnostic biomarkers of ovarian cancer. Gynecologic Oncology 110 13-21. (doi:10.1016/j.ygyno.2008.04.033)

Taylor BS, Schultz N, Hieronymus H, Gopalan A, Xiao Y, Carver BS, Arora VK, Kaushik P, Cerami E, Reva B et al. 2010 Integrative genomic profiling of human prostate cancer. Cancer Cell 18 11-22. (doi:10.1016/j.ccr.2010. 05.026)

Thompson IM, Pauler DK, Goodman PJ, Tangen CM, Lucia MS, Parnes HL, Minasian LM, Ford LG, Lippman SM, Crawford ED et al. 2004 Prevalence of prostate cancer among men with a prostate-specific antigen level $<$ or $=4.0 \mathrm{ng}$ per milliliter. New England Journal of Medicine 350 2239-2246. (doi:10.1056/NEJMoa031918) 
Tomlins SA, Aubin SM, Siddiqui J, Lonigro RJ, SeftonMiller L, Miick S, Williamsen S, Hodge P, Meinke J, Blase A et al. 2011 Urine TMPRSS2:ERG fusion transcript stratifies prostate cancer risk in men with elevated serum PSA. Science Translational Medicine 3 94ra72. (doi:10.1126/scitranslmed.3001970)

Valadi H, Ekstrom K, Bossios A, Sjostrand M, Lee JJ \& Lotvall JO 2007 Exosome-mediated transfer of mRNAs and microRNAs is a novel mechanism of genetic exchange between cells. Nature Cell Biology 9 654-659. (doi:10.1038/ncb1596)

Vickers KC, Palmisano BT, Shoucri BM, Shamburek RD \& Remaley AT 2011 MicroRNAs are transported in plasma and delivered to recipient cells by high-density lipoproteins. Nature Cell Biology 13 423-433. (doi:10.1038/ ncb2210)

Waltering KK, Porkka KP, Jalava SE, Urbanucci A, Kohonen PJ, Latonen LM, Kallioniemi OP, Jenster G \& Visakorpi T 2010 Androgen regulation of micro-RNAs in prostate cancer. Prostate 71 604-614. (doi:10.1002/ pros.21276)

Wang K, Zhang S, Weber J, Baxter D \& Galas DJ 2010 Export of microRNAs and microRNA-protective protein by mammalian cells. Nucleic Acids Research $\mathbf{3 8}$ 7248-7259. (doi:10.1093/nar/gkq601)

Weber JA, Baxter DH, Zhang S, Huang DY, Huang KH, Lee MJ, Galas DJ \& Wang K 2010 The microRNA spectrum in 12 body fluids. Clinical Chemistry 56 1733-1741. (doi:10.1373/clinchem.2010.147405)

Wienholds E, Koudijs MJ, van Eeden FJ, Cuppen E \& Plasterk RH 2003 The microRNA-producing enzyme Dicer1 is essential for zebrafish development. Nature Genetics 35 217-218. (doi:10.1038/ng1251)

Winter J \& Diederichs S 2011 MicroRNA biogenesis and cancer. Methods in Molecular Biology 676 3-22. (doi:10.1007/978-1-60761-863-8_1)

Winter J, Jung S, Keller S, Gregory RI \& Diederichs S 2009 Many roads to maturity: microRNA biogenesis pathways and their regulation. Nature Cell Biology $11228-234$. (doi:10.1038/ncb0309-228)
Xi Y, Nakajima G, Gavin E, Morris CG, Kudo K, Hayashi K \& Ju J 2007 Systematic analysis of microRNA expression of RNA extracted from fresh frozen and formalin-fixed paraffin-embedded samples. RNA 13 1668-1674. (doi:10.1261/rna.642907)

Yaman Agaoglu F, Kovancilar M, Dizdar Y, Darendeliler E, Holdenrieder S, Dalay N \& Gezer U 2011 Investigation of miR-21, miR-141, and miR-221 in blood circulation of patients with prostate cancer. Tumour Biology 32 583-588. (doi:10.1007/s13277-011-0154-9)

Yuan A, Farber EL, Rapoport AL, Tejada D, Deniskin R, Akhmedov NB \& Farber DB 2009 Transfer of microRNAs by embryonic stem cell microvesicles. PLoS ONE 4 e4722. (doi:10.1371/journal.pone.0004722)

Zen K \& Zhang CY 2010 Circulating microRNAs: a novel class of biomarkers to diagnose and monitor human cancers. Medicinal Research Reviews 32 326-348. (doi:10.1002/med.20215)

Zernecke A, Bidzhekov K, Noels H, Shagdarsuren E, Gan L, Denecke B, Hristov M, Koppel T, Jahantigh MN, Lutgens E et al. 2009 Delivery of microRNA-126 by apoptotic bodies induces CXCL12-dependent vascular protection. Science Signaling 2 ra81. (doi:10.1126/ scisignal.2000610)

Zhang HL, Yang LF, Zhu Y, Yao XD, Zhang SL, Dai B, Zhu YP, Shen YJ, Shi GH \& Ye DW 2010a Serum miRNA-21: elevated levels in patients with metastatic hormonerefractory prostate cancer and potential predictive factor for the efficacy of docetaxel-based chemotherapy. Prostate 71 326-331. (doi:10.1002/pros.21246)

Zhang Y, Liu D, Chen X, Li J, Li L, Bian Z, Sun F, Lu J, Yin Y, Cai X et al. 2010 b Secreted monocytic miR-150 enhances targeted endothelial cell migration. Molecular Cell 39 133-144. (doi:10.1016/j.molcel.2010.06.010)

Received in final form 28 March 2012

Accepted 5 April 2012

Made available online as an Accepted Preprint 5 April 2012 